\title{
Expressões contemporâneas da crise estrutural da produção capitalista e seus rebatimentos no Serviço Social
}

Contemporary expressions of the structural crisis of capitalist production and its impact on Social Service

Raquel Santos Sant' Ana ${ }^{a}$

(D) http://orcid.org/0000-0002-2270-5541

Maria Liduína de Oliveira e Silva ${ }^{b}$

(D) https://orcid.org/0000-0002-7904-4836

Maria Inês Souza Bravoc

(D) https://orcid.org/0000-0003-2347-0518

Maria Lúcia Martinellid

(D) https://orcid.org/0000-0001-9124-2846

sta edição vem a público num momento em que os desafios postos pela conjuntura atual recolocam a urgência dos debates e das lutas em defesa da vida e da natureza; a contínua expansão da lógica capitalista coloca limites objetivos à reprodução da vida, da biodiversidade e amplia os desafios daqueles que dependem de seu trabalho para viver. É a perversidade do capital produzindo a insustentabilidade do clima, das águas, da terra e do equilibrio ambiental tão necessário à reprodução da vida. O adoecimento em massa de bilhões de pessoas devido à precarização, à intensificação e à expulsão do mundo de trabalho 
ocorre em paralelo ao cerco e genocídio contínuos às sociedades que não se movimentarm pela lógica do capital e/ou aos segmentos que são continuamente perseguidos e mortos como descartáveis à reprodução da lógica capitalista - tratados como entulhos a serem removidos da límpida transparência das "modernas" relações capitalistas.

Em conjunto com este complexo quadro que vem desde tempos anteriores, novas mediações se apresentam para agudizar a situação, e as pandemias são mais um exemplo desta perversa realidade. A pandemia provocada pelo novo coronavírus, bem como suas várias mutações, trouxe um novo caos e já matou mais de um milhão de pessoas no mundo e quase 600.000 no Brasil. Uma doença ainda pouco conhecida, mas que passadas suas manifestações mais imediatas deixa sequelas que ainda não estão completamente estudadas e avaliadas pela ciência. Paralelamente a isso, agrava-se outra realidade, em proporções também pandêmicas: a fome e ausência de trabalho.

E cada vez mais ficam explícitos os dizeres de Rosa Luxemburgo sobre a necessidade urgente de reversão da sociedade do capital, assim como a necessidade da construção do socialismo, pois este é o único caminho para evitar que a destrutividade capitalista elimine as condições de vida sobre o planeta.

Como muito bem destacam França Junior e também Camargo nos artigos apresentados neste número da revista, o mundo do trabalho vai se configurando de maneira a cada vez mais dividir e adoecer a classe trabalhadora que, submetida a extensas e intensificadas jornadas, segue com vínculos precários ou, como coloca Antunes (2020), grande parte dela uberizada ou descartada do trabalho e tendo suas condições materiais de reprodução profundamente afetadas. E, neste processo que atinge a classe trabalhadora, Camargo destaca o processo de proletarização dos assistentes sociais e as condições objetivas nas quais o trabalho profissional se efetiva. Este fenômeno tem que ser devidamente analisado, afinal, isso envolve não só a materialidade do trabalho profissional, mas também a formação e, em grande medida, dialoga concretamente com 
as reais condições de seguir adiante na defesa do projeto emancipatório que hoje faz parte do Serviço Social brasileiro.

O capitalismo em sua versão monopolista e financeirizada, desde o início do século XXI, vive mais uma crise que não é apenas cíclica, mas também estrutural, e para se manter precisa agudizar o quadro de devastações em prol de sua incessante e irrefreável busca pelo lucro. A hipertrofia do capital fictício sobre o capital produtivo, ainda que crie a fantasia do "dinheiro que gera dinheiro", vai requerendo cada vez mais a superexploração do trabalho, pois é dessa exploração que os diferentes tipos de capital se sustentam, direta ou indiretamente; para agir de forma livre e mundializada, a captura do Estado que segue como seu comitê executivo (Marx; Engels, 1998) é cada vez mais acentuada. Como afirma Netto (1996, p. 22): “O Estado foi capturado pela lógica do capital monopolista - ele é o seu Estado".

Para sustentar estes mecanismos que constroem as desigualdades extremas, é necessário de maneira permanente refazer perversos mecanismos ideológicos de sustentação do insustentável, ou seja, garantir a legitimidade desse sistema sociometabólico. Nele, o crescente pauperismo de grande parte dos seres humanos se dá concomitantemente à concentração da extrema riqueza daqueles que por meio das grandes corporações e seus agentes controlam a vida sobre o planeta. Daí o crescente domínio do capital sobre os vários interstícios da vida, o uso da tecnologia para produzir conteúdo que é utilizado de diversas maneiras, desde georreferenciar os diferentes territórios do globo até naturalizar aquilo que é socialmente construído.

$\mathrm{O}$ avanço das ideias neoconservadoras e mesmo reacionárias ganha vulto numa sociedade adoecida, competitiva e meritocrática; o controle sobre o trabalho e os territórios faz parte dos avanços tecnológicos e segue sem muito questionamento. Ou seja, vivemos uma ambiência política que mais do que nunca requer que possamos compreender o tempo presente e pensar alternativas para além do capital. Neste número, com certeza, o conjunto de artigos dará grande contribuição no sentido de alargar 
o espectro da questão social que permeia a sociabilidade e, também, o trabalho do assistente social como profissão inserida na divisão sociotécnica do trabalho.

Entender esta realidade em seus determinantes fundamentais requer daqueles que se contrapõem à lógica do capital uma perspectiva ontológica concreta, de maneira a permitir a apreensão das mediações que constroem essa sociabilidade e, com isso, identificar os mecanismos que lhe dão sustentação. Diversas particularidades compõem a especificidade da sociedade brasileira que por meio de diversos ângulos estarão presentes nos artigos que estão sendo apresentados.

Ribeiro, nesta edição, vai apresentar as principais determinações da política social na conformação da hegemonia burguesa, com ênfase nas realidades latino-americana e brasileira marcadas pela dependência, norteando as análises sob o referencial da teoria social crítica. Organizam-se as problematizações em dois grandes feixes de análise: política social e dependência e as marcas do colonialismo e da dependência na formação social brasileira (demarcando as incidências destes na trajetória das políticas sociais). A hegemonia é apresentada como domínio político e econômico, priorizando a economia e o fundo público como dois componentes primordiais.

Já Andreazzi, Sancho e Schutz vão abordar a relevante temática das agendas empresariais no sistema de saúde brasileiro no período de 2016 a 2019, que ainda é pouco estudada e precisa ganhar maior visibilidade. $\mathrm{O}$ artigo apresenta questões centrais que influenciam na privatização da saúde.

A análise empreendida por esses autores têm concordância com Bravo, Pelaez e Pinheiro (2018), quando estes consideram que houve uma aceleração da contrarreforma do Estado na saúde no governo Temer e, além disso, uma continuidade das diretrizes da política de saúde entre as administrações de Temer e Bolsonaro. O texto referenciado (2018) coloca que, desde os anos 1990, vivencia-se o processo de contrarreforma do Estado (Behring, 2003), resultando em inflexões no campo das 
políticas sociais que atingem diretamente a saúde pública e o conjunto da Seguridade Social, em consonância com as orientações de mudanças no mundo do trabalho, por meio da reestruturação produtiva (Harvey, 1993) e de redefinição das funções e responsabilidades do Estado, com vista à inserção do Brasil na economia mundializada (Chesnais, 1996).

Nessa linha, há uma forte relação entre as transformações que caracterizam a esfera da produção e o mundo do trabalho e a acumulação na ordem capitalista, associadas ao Estado mínimo, ao fundo público e às mudanças que ocorrem nas políticas sociais contemporâneas que se tornam cada vez menos universais e mais focalizadas, reverberando no desfinanciamento e na privatização das políticas sociais.

Em dois artigos, de Escorsim e Teixeira, a temática do envelhecimento ganha destaque, e ambos evidenciam a relação entre condições de vida e depois as possibilidades concretas da velhice. Teixeira destaca como o processo de envelhecimento decorre das condições objetivas enfrentadas pelos diferentes sujeitos ao longo de sua trajetória. E diante do caos social, instaurado e aprofundado pelo capital, destaca "um quadro de agravamentos dessas condições, que afetará as diferentes gerações, tanto os que hoje são jovens, quanto os que já são velhos, diante da generalização da superexploração, da superpopulação relativa e dos desmontes dos sistemas de proteção social". Escorsim evidencia que os avanços na legislação de proteção social ocorridos na Carta Constitucional de 1988 sofreram uma clara reversão a partir da contrarreforma neoliberal do Estado. E neste processo, como afirma a autora, ainda que a desigualdade afete todos os segmentos da classe trabalhadora, afetará mais drasticamente a população idosa que cada vez vivencia processos mais intensos de precarização da vida frente ao desfinanciamento das políticas públicas e sociais.

Outro tema muito atual e que requer ainda muita reflexão por parte de todos, mas especialmente à categoria profissional, é o assédio moral. Queiroz de Paula, Motta e Nascimento consideram o assédio moral como comportamento intencional e que a pessoa que o pratica tem noção do 
que está fazendo. A competitividade exigida pelo mercado acaba por influenciar essa modalidade de assédio, pois as empresas estimulam que as chefias tratem de maneira hostil seus funcionários em busca de resultados; a concorrência desenfreada, a gestão pautada na frieza e na dureza tornaram um modelo, de forma que a competição inescrupulosa tem sido considerada ferramenta viável de gestão, impondo aos "fracassados" a exclusão dos processos organizacionais, visto que mais relevantes são os resultados e não a qualidade de vida do ambiente de trabalho. $\mathrm{O}$ artigo apresenta as consequências do assédio moral para o indivíduo assediado, para a empresa e para a sociedade. É de se destacar que o assédio, como uma forma abusiva de gestão, pode levar ao adoecimento físico e psíquico do trabalhador.

O assédio é um tema que tem sido objeto de análise de alguns estudos, pois como afirma Barreto (apud Souza, 2019), ele se intensificou muito nos últimos 20 anos em decorrência das mudanças do mundo do trabalho. As humilhações constantes e permanentes àquele que é assediado, a intensificação do trabalho decorrente da exigência do cumprimento de metas são algumas situações que têm trazido fortes rebatimentos na saúde dos trabalhadores, e o artigo de Queiroz de Paula, Motta e Nascimento nos traz novos aportes nesta interlocução.

É intervindo nesse contexto que o Serviço Social realiza pesquisas, ações e traz ao debate da categoria profissional a análise do Serviço Social nesses duros tempos de crise econômica, política e sanitária. Assim, nesta revista, explicitam-se: o debate sobre as condições de trabalho dos/ das assistentes sociais; o trabalho do assistente social no atendimento à população transgênero e travesti; o legado da cooperação científica entre o curso de Serviço Social da PUC São Paulo e as escolas portuguesas; e o sigilo profissional nos Códigos de Ética do assistente social de 1947 e 1965.

Camargo, referenciada em uma pesquisa de doutorado, tece reflexões sobre "as relações e as condições de trabalho de assistentes sociais no mercado de trabalho", apontando as "tendências em curso para o processamento da ação profissional através da tese da proletarização, que 
indica a precarização, a informalidade, a intensificação e a terceirização do trabalho, materializada em níveis salariais baixíssimos, contratos temporários, subcontratações, espaços insalubres, sobrecargas, adoecimentos e humilhações", conforme já referido inicialmente.

Pereira e Lemos analisam os desafios e as possibilidades do trabalho profissional da/o assistente social no atendimento à população transgênero e travesti, utilizando-se de metodologia original e criativa, bastante compatível com os objetivos do estudo. As autoras realizam uma revisão integrativa da literatura, a partir de uma significativa base de dados. Apoiadas nas análises realizadas, em interação com o Projeto Ético-Político do Serviço Social, e em sua vivência profissional, evidenciam a importância de se incluir a temática da diversidade sexual e de gênero no universo do Serviço Social, reconhecendo seu estatuto político e a urgência de uma qualificação rigorosa para atuação com essa população.

Coelho e Guedes analisaram os Protocolos de Cooperação Científica entre a Pontifícia Universidade Católica de São Paulo e as escolas portuguesas, especialmente, em Lisboa e Porto, ocorridos na década de 1980 e que foram fundamentais para a consolidação da licenciatura. Portanto, o legado do Programa de Pós-Graduação em Serviço Social da PUC-SP foi, sem dúvida, absolutamente relevante para que tal conquista ocorresse. Vale ressaltar que em decorrência de tais acordos de cooperação, tornou-se possível o reconhecimento dos cursos oferecidos pelos Institutos Superiores de Lisboa e do Porto, com o grau de licenciatura, bem como a atribuição de titulação acadêmica aos assistentes sociais portugueses.

No último artigo, Toniolo analisa o sigilo profissional nos Códigos de Ética Profissional do Assistente Social de 1947 e 1965. Para tanto, o autor realiza uma profunda inserção na literatura pertinente, estudando as influências que marcaram fortemente a construção dos artigos sobre sigilo profissional, ressaltando certo grau de pioneirismo, por sua natureza e contexto histórico, em ambos os Códigos. Uma originalidade que merece ser destacada nesse artigo é a análise que o autor realiza em relação às questões de natureza conceitual que envolvem sigilo e segredo 
e sua importância no cotidiano do trabalho profissional do assistente social. Outro mérito desse artigo é evidenciar a importância das chamadas "profissões imperiais" - Medicina, Advocacia e Engenharia - na elaboração dos Códigos de Ética das diferentes profissões.

A diversidade das temáticas abordadas nos artigos que trazem a interlocução com o trabalho e a formação evidencia uma profissão que está em movimento, que coloca em pauta suas condições de trabalho, sua ética e enfrenta os desafios de adensar a questão social a partir do enfrentamento a todas as formas de opressão, e este número em particular realiza a interlocução com a temática da população transgênero e travesti.

É interessante observar que a onda conservadora que nos assola, a proletarização do trabalho e da formação colocam novos desafios ao Serviço Social, mas a área segue na produção de análises críticas e fundamentadas numa perspectiva emancipatória, sempre vinculada à materialidade de vida social e ao questionamento da ordem instituída pelo capitalismo. É a consciência de que ainda que possamos estar num momento muito dificil em termos civilizatórios, é importante não perder de vista o que afirma Rosa Luxemburgo, 2009: os desafios não podem ofuscar que a sociedade do capital não será robusta o suficiente para seguir sempre vitoriosa.

Hoje é preciso ter paciência com a história — não estou pensando numa paciência inativa, cômoda, fatalista, mas naquela que emprega todas as energias, que não desanima quando parece momentaneamente bater no granito, e que nunca esquece que a brava toupeira da história cava sem descanso, dia e noite, até chegar à luz.

\section{Referências}

ANTUNES, R. (org.). Uberização, trabalho digital e indústria 4.0. São Paulo: Boitempo, 2020. BEHRING, Elaine Rossetti. Brasil em contra-reforma: desestruturação do Estado e perda de direitos. São Paulo: Cortez, 2003. 
BEHRING, Elaine Rossetti. Fundo público, valor e política social. São Paulo: Cortez, 2021. BRAVO, M. I. S.; PELAEZ, E. J.; PINHEIRO, W. N. As contrarreformas na política de saúde do governo Temer. Argumentum, Vitória, v. 10, n. 1, p. 9-23, jan./abr. 2018.

CHESNAIS, F. A mundialização do capital. São Paulo: Xamã, 1996.

HARVEY, D. A condição pós-moderna. São Paulo: Loyola, 1993.

LUXEMBURGO, R. Socialismo ou barbárie. Organização: Isabel Loureiro. São Paulo, 2009. Disponível em: https://frl.rosalux.org.br/portfolio/pdf-livre-socialismo-ou-barbarie-rosa-luxemburgo-no-brasil-organizado-por-isabel-loureiro/. Acesso em: 11 jul. 2021.

MARX, K.; ENGELS, F. O manifesto do partido comunista. São Paulo: Cortez, 1998.

NETTO, J. P. Capitalismo monopolista e Serviço Social. São Paulo: Cortez, 1996.

SOUZA, E. A. Assédio moral e reforma trabalhista: entrevista com Margarida Barreto. Katálysis, Florianópolis, v. 22, n. 3, p. 641-651, set./dez. 2019 Disponível em: https:// periodicos.ufsc.br/index.php/katalysis/article/view/1982-02592019v22n3p641/41160. Acesso em: 13 jul. 2021.

\section{Sobre as autoras}

Raquel Santos Sant' ANA - Professora e doutora em Serviço Social, vinculada ao departamento de Serviço Social da Faculdade de Ciências Humanas e Sociais de Franca.

E-mail: raquel.santana@unesp.br

Maria Liduína de Oliveira e Silva - Docente associada II do curso de Serviço Social e coordenadora do Programa de Pós-Graduação em Serviço Social e Políticas Sociais. Assessora editorial da área de Serviço Social da Cortez Editora.

E-mail: liduoliveira90@gmail.com

MARIa InÊs Souza Bravo - Assistente social. Doutora em Serviço Social. Professora do quadro permanente da pós-graduação da Faculdade de Serviço Social. E-mail:msouzabravo@gmail.com

Maria Lúcia MARTinelli - Assistente social, doutora em Serviço Social. Docente do Programa de Pós Graduação em Serviço Social da PUC-SP e coordenadora do Núcleo de Estudos e Pesquisa sobre Identidade.

E-mail: mlmartinelli@terra.com.br 